\title{
sciendo
}

\section{The InAdequacy of Classical Regulatory ApProaches IN A COMPLEX ENVIRONMENT}

\author{
Mirko Pečarič ${ }^{1}$
}

\begin{abstract}
The interactions, interdependence, dynamism, diversity, emergency and other elements of complexity should be embedded in legal rules to cope with the complex environment. If it is obvious that the latter is hard to manage with the classical forms of legal rules, this common-sense is tricking us into an insistence on such rules. The complex environment and the people are complex adaptive systems, and such should be also legal rules when applied in such an environment. Public systems should systemically address the environment because the latter is per se blind to rules. The aim of this paper is to give directions towards the use of complex adaptive rules with the enumeration of elements of complexity. Based on the elaborated and included elements of complexity the paper finds that collective decision-making, here named as synomy, presents the appropriate shift from experts to the people and database oracles. The possibility to store and process a large amount of data (with the better statistical prediction) gives collective wisdom preference over the people as individuals, over experts and the classical legal approaches. Based on this the paper presents different rules that are accustomed to different environments.
\end{abstract}

\section{Keywords}

Complexity, Practical and Collective Wisdom, Public Decision-making, IT Democracy, Synomy

"Everything changes, it all stays the same, Everyone guilty, no one to blame, Every way out, brings you back to the start, Everyone dies to break somebody's heart..."

- Motorhead, Love Me Forever

\footnotetext{
${ }^{1}$ University of Ljubljana, Gosarjeva ulica 5, 1000 Ljubljana, Slovenia. E-mail: mirko.pecaric@ fu.uni-lj.si.
} 


\section{Introduction}

Up to what point Cartesian mechanical view of the world and with-it legal certainty as its derivate can reflect the complex environment (in which ageing, energy, big data, climate change, poverty, gender equality, health, migrations, peace, security etc. show surprising instability and non-sustainability)? The more and more global effects on public problems cannot be solved with some kind of formula, even if it would be similar to $E=m c^{2}$; it seems harder to achieve a peaceful solution of some social problem than to correctly calculate a rocket's landing time on another planet. The latter deals with the predictable machines and physical laws, the former with the (un)predictable people, their invisible thoughts and other intangibles. On the other hand, even in natural science - especially in quantum theory and relativity theory - is a matter of degree when one field ends and other begins (Carnap, 1966; Heisenberg, 1958), while this stands even more in social science that deals with living beings.

The above-mentioned problems are thus more the problems of social science (i.e. its ineffective methods) than of natural one. A mechanical approach cannot be successful in dynamic frames - complex matters could be managed only with a similar level of complexity. Ashby (1957) expressed this in the 1960s with its law of requisite variety: a controller can control something only to the extent that it has sufficient internal variety to represent it. This inevitably holds also for general legal rules - they can control the complex environment only with various models, procedures and techniques of similar complexity in a manner of complex adaptive systems. The latter involves components that adapt and learn as they interact (Holland, 2006); as humans are also such systems, we predictably operate in the known, everyday cases, while we otherwise exhibit adaptability, learning, non-linearity, dynamism, exponentiality, emergent and other elements of complexity (this explains why legal gaps cannot be so quickly filled as they can be abused or bypassed). Following that line of thought, the paper's topic are complex adaptable legal rules; based on collective wisdom such rules present the move from more or less static rules towards more dynamic ones. Legal rules should be aligned with conditions in which they are used, and in the dynamic environment they should hance exhibit elements of adaptation and learning. By using the procedural right to decide or to participate in decision-making it cannot be grasped in full what is materially relevant for public participation in the first place. In the absence of visible results (or faced with the still existing or emerging new problems regardless of rules), people less trust in a decision-making system (decreasing voter turnout) and feel their impact is not seen enough. The latter cannot be seen in full, because there are many after-the-voting rules, which affect the people's voices (different volitional systems, coalition government), and possibly because a particular state of affairs was determined without using an appropriate scientific method. If everything is interconnected and interdependent, we all bear a responsibility for what happens to the world and all beings (Dyer, 2020). Because the integrated whole cannot be reduced to smaller units without losing the property of wholeness, partial approaches cannot establish unity. A starting point should be the holistic worldview (Capra, 1997) that sees a thing, a problem or the world as an integrated whole rather than a dissociated collection of parts. 
The first premise of this paper is that the complex, dynamic environment impacts static rules regardless of their democratic core. If classic rules cannot cope with such environment, there is not only a problem of efficiency present but also a large(r) problem of legitimacy: the bureaucratic power not only is unelected but also its frames of public authority do not reflect reality in which people live, which are consequentially wrongly administrated. The existing public structures (of decision-making) can be transparent per se, but they still have (or "hide") their path dependence caused by the very underlying (individualistic) structure (Meadows, 2008). As all structures up to some point operate differently than the formally stated (seen as the bureaucratisation, red tape, unintended consequences etc.) a partial approach paradoxically can be proportionately (when a collective one should be used, when a whole community is addressed) more ineffective with its larger efficiency. It was already said that people are complex adaptive systems, so the second premise of this paper is that reality is 'more real', when complex, i.e. various and diverse people are involved in decision-making. They use their minds and have relationships with others regardless of a formal possibility to do so, and it would be helpful to use their homo mensura element for the benefit of all community. From the systems point of view perceptions per se do not control behaviour, but the people adjust/affect their behaviour/systems to perceive according to their method of questioning (Capra and Luisi, 2014; Feynman et al., 1965; Lanza and Berman, 2013; Maturana and Varela, 2012), according to their meaning and purpose or simply due to their presence. ${ }^{2}$ General legal rules regulate pro futuro, so classical causality cannot be used here; the function of law is here to produce expectations as the ability to make meaningful communications about what ought to happen (Luhmann, 1990, 2004). As the meaning is an organised body of knowledge acquired through a particular scientific method (Capra and Luisi, 2014) in social science this meaning can provide people, who think about the future as Homo prospectus with the focus on expectation, choice, decision, preference and free will (Seligman et al., 2016).

The aim of this paper is hence to emphasise that the formation of legal rules must be accustomed to the different environments, and for the complex one the transfer of elements of complexity should be included into legal rules. This paper's path towards complex adaptive rules begins with the next section with the presentation of two contrary-reflective common-sense predispositions, which 'give the floor' later to elements of complexity. Here also an old way to address complexity in individual matters is presented, while in collective matters there was none until collective wisdom $(\mathrm{CW})$ had been introduced. The latter is addressed in the third section as the shift from experts to the people's interdependence and databases towards a new Nomo-dynamics approach accustomed to the complex environment. $\mathrm{CW}$ as a hybrid approach between the representative and participatory democracy, became 'alive' in the 1947 Jimmy Stewart's movie Magic Town

\footnotetext{
${ }^{2}$ A measuring tool or a sole act of observation is not simply a passive observer but an active participant in the formation of reality. Factors associated with consciousness, such as meditation experience, electrocortical markers of focused attention, and psychological factors including openness and absorption, significantly correlate with perturbations in the double-slit interference pattern. The results appear to be consistent with a consciousnessrelated interpretation of the quantum measurement problem (Feynman et al., 1965; Radin et al., 2012).
} 
(Wellman, 1947) in which the small town of Grandview is presented as a perfect mirror of U.S. opinions. After this, the conclusion follows in the fourth section.

\section{Towards the Complex Adaptive Rules}

\section{Two contrary-reflective common-sense predispositions}

Before some elements of complexity are enumerated a few common-sense understandings are presented from a 'different common sense' perspective. For the start, the democratic deficit cannot be advanced only with active citizenship. If a bad implementation is put aside, the first condition of such citizenship is the presence of relevant information (this is further elaborated in the following sections) and the second is the awareness of cognitive flaws. Human intuition and common sense based on (everyday) experience can fail when something new/different is present. Hume's idea that reason is the slave of our passions (Hume, 2009) got many updates in the primacy of intuition (Baron, 1998; Haidt, 2012; Kahneman, 2013), of actions before reason, reflections and discourse (Kaplan, 2012) based on impulse and desire (Russell, 2015), where demands for common sense are often only the calls for the greater use of intuition (Hammond, 1996; Watts, 2011). Heuristics (Tversky and Kahneman, 1974), overconfidence (Dunning et al., 1990), ex-post rationalisations (Varoufakis, 2002) and other biases muddle reason with emotion; in fact, 'there is no inner contrast between emotion and reason: emotion is the main source of motivation steering us towards certain goals; it can steer a considerable power of reason towards the goals that it gives rise to' (Simon, 1997, p. 91). Even more, emotions form in the amygdala (a small, two-sided structure in the temporal lobe of the brain) that causes emotional learning and evaluation, particularly in provoking emotional responses to fear or aggressive stimuli (Adolphs et al., 1998). As people do not make decisions based solely on reason, they should be aware of caveats like the confirmation bias, ex-post rationalisation, and other systematic errors in thinking. One of them could be easily diminished: when one answer and its opposite appears equally obvious, then 'something is wrong with the entire argument of "obviousness"' (Lazarsfeld, 1949, p. 380). In the world of growing complexity one-size-fits-all rule (or even many rules) is even less the right one than before. This stands also for principles, as for each one can find an equally plausible contradictory principle (Simon, 1997). As people raise different principles in different circumstances, conditions must be specified. Context dependence is needed to deduce a fragile meaning of abstract words in practice, as the latter serves for the extraction of regularities, conceived in abstract concepts. To progress, one could follow the frequency of cases, define concepts and criteria and assign weights to them. On the other hand, there are human cognitive errors present, and there are thus different contexts. How the latter are reflected in legal rules?

The above-given Lazarsfeld's quote can be paraphrased: when all (active and 'democratic') sides have equal or similar (contra) arguments, a final decision is probably wrong. It disregards the minority (that could be almost as big as the majority), and as it is rational in statistics to consider the base rate (or prior probability), decision-making processes should consider also the minority to gain a full decision's spectre (and thus a result 
that reflects all 'numbers'). Only the latter can reflect what happened relative to what it could, but did not (the use of Bayes theorem is helpful here), or what is not so obvious despite its 'common-sense obviousness'. Notwithstanding the numerous papers on human errors, they are similar as they were in the past: they usually do not use experimental techniques, rely primarily on what public servants (as the usual scribers of draft legal acts) think, who rarely include comparative (and hence more objective) observations (scientific researches), and deal with aggregates rather than with integrated (averaged) results. Where is common sense in this? This (unlike in natural science) shows social processes as vivid and cyclic, where people have their own and constantly-changed wills according to their needs, interests, emotions and reason vis-à-vis the given environment, i.e. the understanding of the latter.

\section{Elements of (human) complexity}

When individual parts interconnect, they became interdependent, which leads to selforganizing networks with dynamic components. Interdependence is well-known also as the six degrees of separation concept, whose first proponent was Frigyes Karinthy in his 1929 short story, Chains. It is known also as the small-world phenomenon that formalises Karinthy's idea that "you are only ever six "degrees of separation" away from anybody else on the planet' (Watts, 2018, p. 4). ${ }^{3}$ Interdependence becomes dynamic when over time two or more agents interact and produce changes based on their interaction. ${ }^{4}$ And in the dynamic, complex networks the rule is nonlinear behaviour (Willy et al., 2003), where the law changes concerning the scale of variables (parameters) and as such is the distortion of the linear graph or the proportionality relation.(Yoshida, 2010) When people connect, the elements of complexity can be found in the nonlinearity, communication, emergence, diversity and prediction. The core attributes of most dynamical systems are thus nonlinearities (a value of one part is here not a weighted sum of another part) which are rarely included in the law.

Nonlinearities can be caused also by the speech, writing and argumentation; they all are based on communication, on the transmission (lat. communicare, to share) of meanings from one person/group to another through the reciprocally understood signs, symbols and semantic rules. ${ }^{5}$ Communication has its etymological root in "commun" (from which are derived also words like 'commune, community, commonage or commonalty') focusing on the integrated body or synchronised movement of members, in the absence of causality (people are not forced to do something but moved by ideas). In the paraphrased words of Aristotle's Rhetoric (2012) (the art of communication) logos, ethos and pathos should be included also in decision-making to have 'the art of regulation'.

\footnotetext{
${ }^{3}$ Milgram (1967) has in cooperation with other researchers examined the average path length for social networks of people in the United States. Out of 296 letters, 64 of them reached the target destination with the average path length was around six.

${ }^{4}$ The famous economist Joseph Schumpeter has conveyed his argument for a dynamic approach in economic modelling by coining the phrase that neglecting dynamic aspects is like performing Shakespeare's Hamlet without the prince of Denmark (Grass et al., 2008).

${ }^{5}$ What one person can just say at one end of the world can be considered deeply by the other person at the other end of the world.
} 
Aggregation not only exhibits nonlinearity but inevitably leads also to the emergence of new properties, behaviours or meanings that are produced in interaction with other parts. Emergence (as the default rule in any kind of aggregation) is present also in legal rules (that are interpreted in their connections and combinations by default); together with the exponential function, nonlinearity and diversity they exhibit conditions away from legal certainty. Diversity often enhances the robustness of complex systems (the ability to maintain functionality), it drives productivity and innovation (Page, 2010), and is better than echo chambers or information cocoons (Sunstein, 2006, 2017) in which people hear what they want to hear. It is the diversity of perspectives that makes the magic work (Tetlock and Gardner, 2015).

To understand complex systems diverse and/or 'many models approach' is needed to reason, explain, design, communicate, act, predict, and explore them (Page, 2018). Regulation can frame the flow of such variety - but it should be similar to the variety itself. To address variety Ashby's law of requisite variety (Ashby, 1957) is needed: only

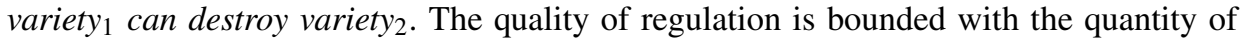
information that is transmitted in a certain channel. Based on requisite variety internal forms should be as complex as the external ones to be effective. To base decisions on it, there should be a system/model present in the first place and its mechanisms known.

The interdependent, dynamic, complex and nonlinear interactions of parts open the question of their direction, coordination (the ability to communicate) and control (trust) on which the classical (Cartesian or mechanical, i.e. the non-adaptable and non-learnable) regulatory approaches cannot be the right answer. The inefficiency of static rules comes not only from the linguistic inversion of 'static', but primarily (and regardless of the word) from the above-mentioned (basic) meanings of communication and the stated elements of complexity. Static rules neither can predict nor prosper. Humans can. There should be some other mechanism instead of the classical common sense or intuition of politicians or experts based on experience to regulate the dynamic, more and more interconnected and thus globalised future. To better mimic complexity than classic rules, such mechanism should include/reflect the people as the vibrant, living community.

\section{The old way to address complexity in individual matters}

In the absence of globalised, connected world Aristotle used the notion of phronesis that means "in different contexts, "intelligence", "good sense", "prudence", (Woods and Aristotle, 1992, p. 47) - which is usually translated as "practical wisdom" (PW) - for the right use of what, when, where, who, with what, how and for what purpose in a particular/personal context. PW depends on the ability to perceive a situation, to have appropriate feelings or desires about it, to deliberate about what was appropriate in such circumstances, and to act (Schwartz and Sharpe, 2011). PW needs mental skill or the ability to correctly frame a situation; concerning other people, it is known as empathy. It means understanding (or taking the perspective of) what another person feels (to recognise what is important or what facts are relevant for him). Aristotle listed PW among virtues as a mean state between unscrupulousness and unworldliness, because 'in all cases, the mean 
relative to us is best... For opposites rule out one another; the extremes are opposed both to one another and the mean because the mean is each one of the opposites in relation to the other' (Aristotle, 1992, p. 16). PW thus looks for a mean state, and can as moderation be seen as the principle of individual life. For the later discussion, it is relevant the mentioned virtues and PW are context-dependent (Schwartz and Sharpe, 2011) and aim towards a mean state based on opposites that rule out one another. Decision-making is synonymous with PW and vice versa: the latter gives 'commands since its end is what should or should not be done, while judgement only judges' (Aristotle, 2004, p. 114). Rules and incentives thus need PW to use them in life vis-à-vis the context, moral virtues and means with which goals can be achieved. PW can be present in the best people, but - maybe faced with the constraints of small contexts that one person can have - Aristotle placed the superiority of the collective in front of a few excellent people:

For the many, who are not as individuals excellent man, nevertheless can, when they have come together, be better than the few best people, not individually but collectively, just as feasts to which many contribute, are better than feasts provided at one person's expense. For being many, each of them can have some part of virtue and practical wisdom, and when they come together, the multitude is just like a single human being, with many feet, hands, and senses and so too for their character traits and wisdom. That is why the many are better judges of works of music or of the poets. For one of them just one part, another another, and all of them the whole thing (Aristotle, 1998, p. 83).

On issues that affect the community of people, a better solution than individual PW can be $\mathrm{CW}$ that can more precisely elaborate a wider context of things, which per se (as context) implies systemic approach. 'This is, in fact, the root meaning of the word "system," which derives from the Greek synhistanai ("to place together"). To understand things systemically literally means to put them into a context, to establish the nature of their relationships' (Capra, 1997, p. 27). People in groups can through the multitude of PWs generate CW that enhances the capacities to perceive, reason and decide on a collective's questions. Additional reasons the multitude rather than the few best people should be in authority were for Aristotle also the exclusion from office and poverty of the many: ' $[t]$ he remaining alternative, then, is to have them participate in deliberation and judgement' $(1998$, p. 83). In individual/personal things $\mathrm{PW}$, and general/common matters $\mathrm{CW}$ should hence prevail. Many minds, deliberating together, can improve the quality of the few best; this could happen when special conditions/circumstances are present, and with them deals the next section.

\section{Collective Wisdom - Its Preconditions and The Shift from Experts to The People and Databases}

To begin with, the dilemma of the value of experts over citizens as laymen must be dispelled in some cases. The sole enumeration of conditions for $\mathrm{CW}$ can be the ex-post rationalisation and/or choice-supportive bias if results would not confirm the advantages of CW. But they do. The complex environment can be addressed with efforts to aggregate information that shows impressive accuracy (Ayres, 2007; Dawes, 1979, 1979; Galton, 1889; Malone, 
2018; Meehl, 2013). The below-given conditions act contrary to crowd thinking that exhibits sentiments like the impulsiveness, mobility, irritability, suggestibility, credulity, exaggeration, ingenuousness, intolerance, dictatorialness, conservatism and low morality of crowds (Bon, 2001). Despite honourable causes that lead people to join masses, deliberation and opinion could suffer from the personal flaws (anchors, ignorance, framing, loss aversion, under/over-confidence, reputation, hindsight and other cognitive biases) that can emerge in the herd behaviour, social conformity (in esprit de corps) and group thinking (Janis, 1980); these conditions can go to extremes due to group polarisation and cascade effects (Sunstein, 2006, 2009). Quiet members regardless of their intelligence are usually put aside in the face of the louder (emotionally or otherwise more appealing), but less intelligent members. It is thus important that a systematic exploration of relevant issues provides the exploration also of unshared information that does not support members' existing references (Stasser and Titus, 1985). Because - based on experimental evidence even a mild social influence can undermine CW effect (Lorenz et al., 2011) it is important to know elements that (can) lead to CW. The first of them is evolution itself.

Evolutionary, tiny changes. When Charles Darwin had studied Adam Smith (Ridley, 2017) he could have found his idea on the invisible hand, that individual self-interest may indirectly benefit society more than direct (public) actions. Parsons also used the evolutionary approach in idea that social systems may evolve to a state in which they can better deal with environmental pressures when they improve the ability to adapt (Parsons, 1991); based on further occupational differentiation they can cause the emergence of specialized organizations with 'legitimate authority' under a system of normative order(1985). For Parsons (Parsons, 1985) the functions of any system of action (pattern-maintenance, integration, goal-attainment, and adaptation) are the link between the structural and the dynamic aspects of the system. As humans (also as systems) evolved based on evolution, also 'collective decision-making processes are par excellence of evolutionary processes in the social realm... [that] develop because of the selection pressures exerted on it' (Gerrits and Marks, 2017, p. 6). Decision-makers are frequently limited by their ability to scale, weight and adapt to the changing contexts. In the light of the evolutionary approach, classical public deliberation could be less effective because people many times uncritically adapt their meanings to the others' meanings, (and less to their actions) and do not know about other (silenced or unspoken) possibilities. All parts de facto interact and thus have an impact on the whole; the latter (the community of people) cannot be effectively addressed when only some parts decide.

Evolutionary changes express diversity that is seen in the (un)critical and (in)dependent thinking on which actions should be re-tested. Without diversity, 'in the presence of change it reduces the robustness of the system' (Johnson, 2002). When collective integrates (too many) unchangeable units into it, the system's robustness to survive is at risk due to the lower parallel connections that maintain communication and coordination with the external environment. The diversity and independence (that are necessary for a crowd to be wise) are to Surowiecki (2005) conditions for CW that should avoid the problems of cognition, coordination, and cooperation. These conditions should be enabled through a formal system that connects all the members in a way that the high-ability members 
are not limited with the low-ability ones and vice versa (through e.g. negative correlation or statistical regression), where the formal system can change its patterns of doings through the quick extraction of new data, newly enacted/changed decisions and actions, all connected with feedback loops.

It was already that sole communications can cause nonlinearities, so it comes as a rule that dispersed information of the public is always diverse at the same time. Ability to adapt based on such information lead Hayek to claim that "civilization rests on the fact that we all benefit from knowledge which we do not possess. And one of the ways in which civilization helps us to overcome that limitation... is by the utilization of knowledge which is and remains widely dispersed among individuals' (Hayek, 1998, p. 15). Experts inevitably lack many tiny and diverse pieces of information that the public has. The first could consider what is called "regulatory due process" and understand public comment as the crucial, vital and fundamental safeguard against errors. This per se cannot avoid the mentioned group thinking, because it must be further processed - it is not about formally higher political legitimacy but about the substantive avoidance of errors (that lead to the former). Active citizenship from the 'bottom-up' approach is based on greater pressure of citizens and users for better service as the 'top-down' control and inspection can deliver, but it is not enough. The system is also needed to process all diverse information into a meaningful whole that does not disregard anybody's opinion but engraves it into a final decision. Legal rules could also exhibit this when the system will transfer nomo-statics into nomo-dynamics.

This kind of system should systematically explore and balance relevant aspects of group members. The uncritical creation or maintenance of thoughts based on opinions or endorsements of others without considering a full range of different and dissenting opinions (especially if they are grounded on facts) leads towards mistakes, regardless of the best logical arguments. Diversity should be the unbiased entrance condition for a decision's acceptance. Page enumerates four procedural conditions (the problem has to be hard; the people have to be smart and diverse; the group size has to be bigger than a handful and chosen from a large population) under which group can outperform individual professionals (Page, 2008, p. 162), ${ }^{6}$ who are as a group usually (in social science) no superior to ordinary people (this idea is elaborated in the following subsection), apparently because each of individual predictions contains bits of truth mixed with various errors, where these bits add up to a larger truth, whereas errors cancel each other by negative correlation. The more diverse opinions are represented, the more complementary bits of truth can be combined. Owing to the law of large numbers logic the average or median result should be closer to the expected value and is higher than individual members' scores. Opposites cancel out one another. Regulators need to understand how people think and respond to regulated matter; without considering many various and unshared information regulation will express only the limited experts' perspectives and based on them also similar results (that can also cause many unintended consequences). Participation is not worthy only due to its democratic element, but also - under the given conditions of CW -

\footnotetext{
${ }^{6}$ Surowiecki also gives four conditions that characterize wise crowds: 'diversity of opinion, independence, decentralization, and aggregation' (Surowiecki, 2005, p. 10).
} 
due to its better estimation of reality. Rousseau is known by his ideas on direct democracy, but it is less known he spoke about the "extrapolated democracy", 7 similarly, as Aristotle did about the virtue of character; ${ }^{8}$ they both talk on opposites that cancel out one another (now known as the mutual cancelling regression analysis). Under specific conditions, groups can be more intelligent than individuals. The reason seems to be in the mix of right and wrong answers, where the wrong ones tend to cancel each other out, leaving the right ones (O'Reilly, 2010), ${ }^{9}$ and the same could stand also for their cognitive biases (as they are also balanced during a process).

The presence of $C W$ factor and social intelligence. Woolley et al. have in the Science journal presented two studies (with 699 people working in groups) in which they found evidence of $\mathrm{CW}$ factor that does not correlate with the average or maximum individual intelligence of group members, but with 'the average social sensitivity of group members [as measured by the Reading the Mind in the Eyes test], the equality in distribution of conversational turn-taking, and the proportion of females in the group' (Woolley et al., 2010, p. 686). Their conclusions are contrary to group polarisation and cascade effects. Engel et al. (2014) found CW was correlated with the individual group members' ability to reason about the mental states of others (the social ability called 'Theory of Mind' or ' $\mathrm{ToM}{ }^{1}{ }^{10}$ which is by its content present already in Aristotle's PW) also in online environments, where $\mathrm{CW}$ factor characterizes group performance as well as for face-toface groups. The online group communication only via text is enough when the ability to reason on the mental states of others can fit into the general concept of emotional (Engel et al., 2014), or wider social intelligence. ${ }^{11}$ Diversity is thus secured when consensus is 'off the table', and CW when all persons' independent and impartial inferences are

\footnotetext{
${ }^{7}$ There is often a great deal of difference between the will of all and the general will; the latter regards only the common interest, while the former has regard to private interests, and is merely a sum of particular wills; but take away from these same wills the pluses and minuses which cancel one another, and the general will remains as the sum of the differences (Rousseau, 2002, p. 142).

${ }^{8}$ In all cases, the mean relative to us is best; for that is as knowledge and rational principle prescribe. And in all cases that also produces the best state. And this is evident from induction and argument. For opposites rule out one another; the extremes are opposed both to one another and the mean because the mean is each one of the opposites concerning the other: the equal is larger than the smaller but smaller than the larger. So it must be the case that virtue of character is concerned with certain 35 means and is itself a certain mean state (Aristotle, 1992, p. 16).

${ }^{9}$ E.g. Michaela and Juliana have predicted places on which Maggie (6), Cole (5), and Brody (1) will achieve in an upcoming event. Michaela/Juliana classified them on $6 / 10^{\text {th }}, 3^{\mathrm{rd} /} / 7^{\text {th }}$ and $5^{\text {th }} / 1^{\text {st }}$ place. Errors are squared so that negative errors and positive errors do not cancel one another out; Michaela's error is $(6-6)^{2}+(3-5)^{2}+(5-1)^{2}=0+4+16=20$. Juliana's error is $(10-6)^{2}+(7-5)^{2}+(1-1)^{2}=16+4+0=20$. Their average error is 20 , while they collectively predict Maggie/Cole/Brody will take $8^{\text {th }} / 5^{\text {th }} / 3^{\text {rd }}$ place $(8-6)^{2}+(5-5)^{2}+(3-1)^{2}=4+0+4=8$. Their collective prediction is more accurate than either of their predictions. If more guessers were added, their predictions will be even more accurate. More on prediction diversity see (Page, 2008, pp. 197-235).

${ }^{10}$ An individual has a theory of mind if he imputes mental states to himself and others, like purpose or intention, as well as knowledge, belief, thinking, doubt, guessing, pretending, liking, promising, trusting and so forth. A system of inferences of this kind is viewed as a theory because such states are not directly observable, and the system can be used to make predictions about the behaviour of others (Premack and Woodruff, 1978).

${ }^{11}$ Social sensitivity can be social intelligence that is organized into social awareness (what we sense about others) and social facility (what we then do with that awareness) (Goleman, 2007).
} 
elaborated and correlated. Diverse and independent opinions can, therefore, be present in emotionally and socially open and unbiased people as in large databases, where negative correlation diminishes the people's biases on both sides. A preference to use one or another is conditioned with the availability of data (the latter), values (the first) and uncertainty (both). It seems social ability is (along with the independence and diversity) needed to form CW. People who have developed social abilities (ToM), who are cautious, humble, nondeterministic, open-minded, reflective, numerate, pragmatic, analytical, with diverse views, probabilistic, thoughtful updaters, checking and thinking on biases, are known as superforecasters (Tetlock and Gardner, 2015) (they could fit also in the Rawls's veil of ignorance in which persons have no knowledge on their characteristics, social and historical circumstances, and use only their mental powers to solve a problem). Tetlock and Gardner (2015) have based on empirical tests confirmed that when such people are grouped, they not only beat individual experts but even prediction markets as a form of CW.

\section{Equation vs. expertise}

Decision-makers many times neglect the long-known fact that a group of individuals can make statistically more reliable predictions than individual experts. The latter as individual persons, can neither store in their memories, nor mentally process a large amount of data. Galton was the first who demonstrated that the median estimate of a group can be more accurate than experts (Galton, 1907). This (opposite) approach is based on the scientifically validated idea of a team source and statistical equations (Dawes, 1979; Galton, 1907; Grove and Meehl, 1996; Meehl, 2013; Page, 2008; Woolley et al., 2010), while the classical majority voting is similar to correlation analysis that tells us only the interdependence among two variables, while (in CW) regression analysis tells us about the impact of one or more variables on the dependent variable. In the $\mathrm{CW}$ version of democracy, independent variables are citizens, who without knowing on others' votes, vote as individuals in their private lives, while these votes are then processed to show their mean state. 'In sharp contrast to traditional experts, statistical procedures not only predict, they also tell you the quality of the prediction. Experts either don't tell you the quality of their predictions or are systematically overconfident in describing their accuracy' (Ayres, 2007, p. 116). This distinction means the shift from experts to evidence-based decisionmaking that specifically states the amount of data, weights, prediction, and its quality. The 'experts camp' also tries to use artificial intelligence in the 'rule-based' (if $X$, then $Y$ ) approach that collapses when various possible or new choices are possible, while in the 'neural networks' camp, the computer is not taught of rules that had been envisioned by a human brain, but reconstructs the human brain itself: based on lots of examples of a given phenomenon neural networks themselves (computing power plus algorithms) identify patterns within the (large amount of) data (Lee, 2018). Already Gulick in Notes on the theory of organisation not only presented the functions of the chief executive with the now well-known POSDCORB acronym (Planning, Organizing, Staffing, Directing, Coordinating, Reporting and Budgeting), but he also warned on experts' caveats (caveamus expertum) who has the 
tendency to assume knowledge and authority in fields in which he has no competence. In this particular, educators, lawyers, priests, admirals, doctors, scientists, engineers, accountants, merchants and bankers are all the same-having achieved technical competence or "success" in one field, they come to think this competence is a general quality detachable from the field and inherent in themselves. They do not remember that the robes of authority of one kingdom confer no sovereignty in another; but that there they are merely a masquerade (Gulick, 2003, p. 11).

Shanteau's theory of expert competence (1992) is based on a distinction between the dynamic and the static domain, where decision and cognitive researchers should focus on both. Taleb (2010) uses this distinction as a practical, rule of thumb solution for the expert vs. the non-expert dilemma, i.e. what moves (and thus requires knowledge, episteme) and what does not move (and does not require knowledge, but only craft). Experts who tend to be not experts are for him 'stockbrokers, clinical psychologists, psychiatrists, college admissions officers, court judges, councillors, personnel selectors, intelligence analysts... economists, financial forecasters, finance professors, political scientists, risk experts... and personal financial advisers' (Taleb, 2010). ${ }^{12}$ Decisionmakers in the public domain (that moves and changes daily) tend not to be experts if they do not incorporate dynamic elements into their decision-making. For things 'that move' data are needed, so experts without knowing them, cannot (solely based on past experiences) predict well what will/could happen. Science should express the richness of nature and assemble facts through a variety of disciplinary lenses, in ways that can support, and are causally indistinguishable from, a range of competing, value-based political positions (Sarewitz, 2004). They should openly associate science with possible courses of action (Pielke Jr, 2007).

That 'the common man is a better judge of his own needs in the long run than any cult of experts' (Gulick, 2003, p. 11) was further advocated by Slovic (1987) because laypeople have a much richer conceptualisation of risk than experts. Faced especially with the lack of consensus on values and high uncertainty experts should be the honest brokers of policy alternatives (Pielke Jr, 2007) where they present alternatives, but live to decision-makers a possibility to reduce choices based on their preferences and values. The higher are risks the larger is the duty to include along with experts also the groups of experts and people, who can provide more diverse information. Decisions supported with the numerous, quantitative data and more or less frequent (not very rare) events are often a better predictor than decisions based on experts and their experience. The various and independent people can be better predictors than experts (due to e.g. their overconfidence, confirmation bias, disrespect of base rate, narrow frames, the rigid and inflexible minds unprepared to weight or ponder personal as well as contrarian opinions, who do not update their beliefs in response to new facts, on rigid insistence on logic/experiences where common sense can fail in new conditions, where diligence in analysing the available information could show other aspects, or simply due to subjective judgement that is not calibrated, weighted with other various and diverse opinions). For the enlisted reasons

\footnotetext{
12 The enumeration is similar to the above-given Gulick types of experts.
} 
experts can 'score less than chimpanzees' because they guess randomly (Rosling et al., 2018; Tetlock and Gardner, 2015).

Along with one or many group wisdoms, there is also big data wisdom; deep learning based on algorithms can give new knowledge on data correlations (Christian and Griffiths, 2016; Lee, 2018). Regression does not have troubles with updating beliefs in the face of disconfirming information. Unlike experts, statistical regressions (based on collected data or the people's inputs) do not have emotions (feelingless data) and put appropriate weights upon various factors. Experts could make better decisions when they are acknowledged with results of statistical prediction (as statistical support), but they still disregard a prediction and stick to their convictions. Before a question when to leave a final decision to statistical and/or model prediction instead of experts, a track should be kept how experts decided in disregard of predictions' suggestions. The best optimization would be probably to add their expert evaluation in the statistical equation (where the over/under-confidence cancels out each other) which importance of use rises with the importance of a problem.

\section{Collective wisdom approach towards Nomo-dynamics}

Isaac Newton in his reworking of Bernard de Chartres' quotation famously stated, 'If I have seen a little further it is by standing on the shoulders of giants' (Newton, 1675). The scientific community has progressed many times by building on previous discoveries, while this is not evident neither in the majoritarian nor in the proportional electoral systems. Representative democracy emerged in the 18-19th century due to various reasons (among them were/are the lack of time, expertise, large distance, disinterest, a lack of motivation, etc.), but in the era of information technology (IT) at least the lack of time and distance can be left out of consideration. Nowadays the citizens' perspectives, choices, incorporating beliefs and cultural backgrounds should be included in public decision-making, especially when this is not so hard to do. Although individually each person has diverse knowledge or differing beliefs, their $\mathrm{CW}$ provides more accurate data. This could be sine qua non of the new 'smart legitimacy'. When authority and openness walk hand in hand, mechanisms can be created to extract $\mathrm{CW}$ from diverse participants. The complexity of relations makes things complicated, so a smart assembly of parts to form the manageable (able to change), systemic is needed. Even if the elaboration of relations cannot be known with full mathematical precision (like all details of the plane's operations are not known) their overall understanding can be. Based on the mentioned elements of complexity, diversity and variety in the environment, only the similar conditions in the society can address them - through some system. And here (see Figure 1) people and their data come to the fore in various ways: 
Figure 1: Collective wisdom and its alternatives

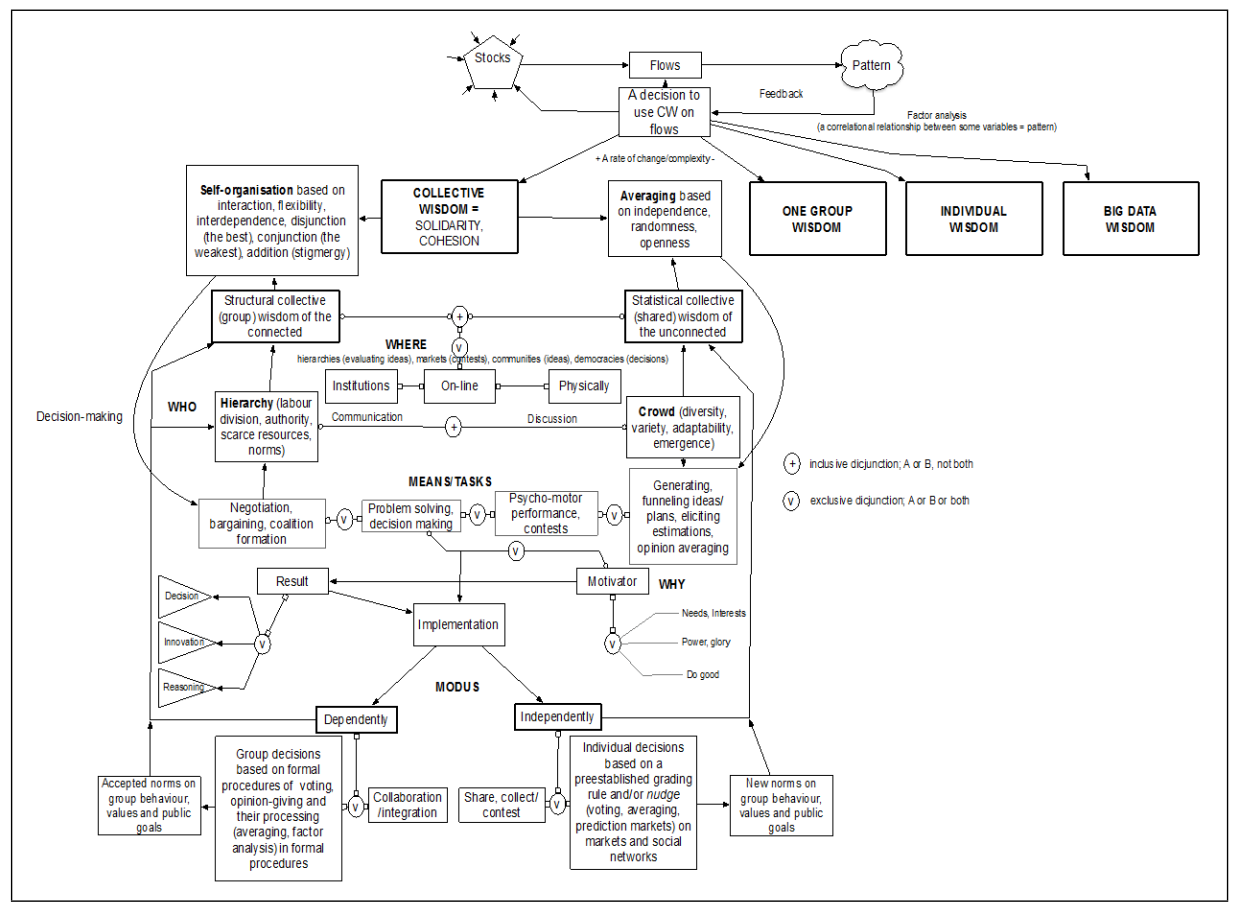

There are a) simple, b) complicated and c) more complicated ways to harness CW: a) and $\mathrm{b}$ ) can be made from the unconnected individuals, who (independently and without knowing each other's answers) provide data for other purposes (in the open databases) or to solve a specific problem, while the more complicated ways can be made with the connected individuals, who act with a certain degree of mutual dependency (from the most loose connection, where results of others are seen [which can affect decisions of the later opinion-givers], to the more connected (where social ability comes to the fore) and the most connected, where the later opinion-givers mimic the previous ones. The options a) and b) are based on data aggregation and statistical analysis, while c) results in self-organisation processes. The examples of $\mathrm{a} / \mathrm{b} / \mathrm{c}$ are the open data (portals)/public forums/communication (via pheromones of mimicking insects) that gives and changes weights of given alternatives. These options circulate the notions of 'social machines', 'social computing' as a crowdsourced media reports on public problems (Shadbolt et al., 2019) or 'social collective intelligence' as a mix of CW and social informatics (Miorandi et al., 2014) that includes the ideas of hybrid computing (people and machines working together to create new types of problem-solving ability, from peoples' everyday use of their mobile connection to data, algorithms and social networks), adaptivity and learning (gaining knowledge of how the system responds to different circumstances and using that to readapt). One of such examples is the Smart Society project (Smart Society Project, 
2017) as a socio-technical ecosystem, in which the physical and virtual dimensions of life are intertwined and where people interact. All alternatives of $\mathrm{CW}$ could serve as an input for flows that together with the stocks, patterns and feedback represent the system (the upper part in Figure 1). CW could be the answer on the question on '[h]ow much energy and creativity might be unlocked if all people in an organization feel in control' (Malone, 2003, p. 63)? Regarding the implementation steps, the government could establish different public platforms on which the people could provide their opinions on public matters. This citizen-centred approach could reframe discussion between autonomy and paternalism towards the shared decision making, collaboration or the calibration of public interest according to the citizen's inputs, towards partnerships among the public institutions, citizens and communities. Such an approach could promote practices that will more likely nurture $\mathrm{CW}$ than simply proclaim the principle of autonomy.

One of the most obvious ways IT can help 'is by helping groups remember and share the lessons that individuals have learned separately' (Malone, 2018, p. 233). CW can better adapt than the classical static rules due to its mimicking of complex adaptive systems. Among the usual (more mechanically-connected) ways of reaching $\mathrm{CW}$ and/or collective decisions are the charrette, focus groups, future search, the Samoa circle or the Delphi method, while the IT (especially Internet) - based (unconnected people as individuals, but statistically [just] aggregated) ways are many forms of crowdsourcing that integrate the creative energies of online communities into day-to-day operations (to rate or design product or solve problems) of many organizations (Brabham, 2013; Grier, 2013), like the prediction markets (e.g. the University of Iowa's Iowa Electronic Markets, the Hollywood Stock Exchange, FantasyScotus, Amazon Product Review Tool, customers' [books, films, photos] ratings) supported with the various decision-making software based on more the collaborative decision-making, big data and machine learning (e.g. Decision Lens, LexPredict, Foldit, Climate CoLab). From the systemic (and formal, institutional) point of view, self-interest could not be at odds with the greater good, if a public model of " $\mathrm{CW}$ decision-making" (CWDM) is organised. One of the first was examples was participatory budgeting that started in Porto Alegre, Brazil, in 1989, as an anti-poverty measure that helped reduce child mortality by nearly $20 \%$. Since then PB has spread to over 3,000 cities around the world (Oliveira, 2017). Based on the mentioned examples a political organization based on the CWDM can be a new way to address complexity. How much time Homo politicus has left to realise this (especially in the more and more connected, intertwined problems that are more and more present on the global level)?

In the meantime, along the experts and MPs (public assemblies), other ways can express a larger diversity than the first two; this can be done with the committees or groups of experts, with an individual that enables/builds diversity into his decisions (by using Bayes theorem or Bayes nets, a Markov chain or other stochastic models) (Carrier, 2012; Edwards et al., 2007; Gamerman, 1997; Nielsen and Jensen, 2007), while CW (through the aggregation and statistical analysis of independent, individual opinions) probably bits them all. CWDM emphasizes consensus-building; it does this not by the 'winner-takes-all' dynamic of majoritarian decision-making, but by the independent, diverse and analysed citizens' inputs. In the majoritarian case, a minority will probably do everything in its 
power to undermine the majoritarian decision (for the important cases, the classical legal theory provides solutions in a higher majority or in negotiation), while in the second all are represented in it. This way can be named as synomy (syn, together and nomos, laws) or the wisdom of collective decision-making. This kind of collective decision-making does not disregard an opposing part: it is included in a decision.

\section{Figure 2: Different rules for different environments (own construction)}

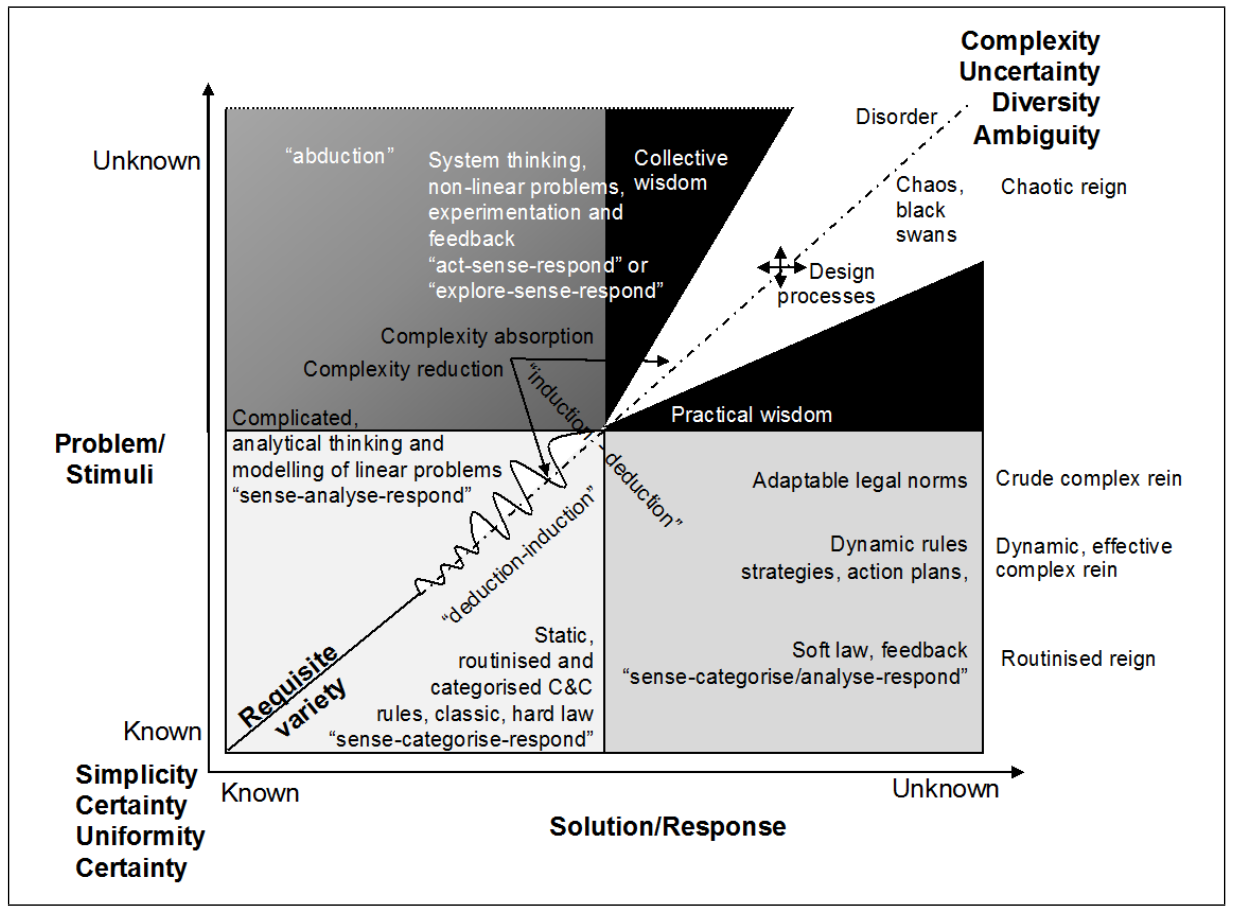

CWDM should thus be able to i) process data obtained from the real world (based on [stochastic] indicators); here a citizen scientist as a volunteer comes to the fore who collects and/or processes data as part of a scientific enquiry (e.g. the Christmas Bird Count as a major source of scientific data on trends in the status of bird species in North America, the Evolution MegaLab and OPen Air Laboratories - citizen science projects invite the public to take part in scientific investigations by contributing data, processing data or both (Silvertown, 2009; Worthington et al., 2012); ii) record measurements that uncover patterns between interactions; iii) enable/change different and independent input values and follow how patterns change; iv) compare results of patterns vis-à-vis predictable scenarios based on the average or median result and/or various (publicly-known) algorithms and v) adapt new decisions/scenarios. If citizens' inputs are included in such (or similar) way in decision-making, CWDM is present (Brabham, 2013; Briskin et al., 2009; Landemore and Elster, 2012; Surowiecki, 2005; Tovey, 2008) provided that in search for optimal decisions includes the patterns, network, connections, diversity, aggregation and averaging (instead 
of singular decision-makers, deliberation, division, disconnection and sameness). The power of $\mathrm{CW}$ can due to mutual cancelling remove the behavioural and other biases (Ariely, 2008; Kahneman, 2013); due to the higher calculation power over brains' limits of processing power (Marois and Ivanoff, 2005) CW can be a better answer for the complex environment, with its numerous combinations. Given the (un)known problemsolution relations there are at least four possibilities for which different rules can be (proportionately with requisite variety) used, as it is seen in the Figure 2.

The environment evolves in its own (systemically-interconnected) ways, and it does not consider formal (democratic) decisions automatically. The latter must hence address the first accordingly with the similar level of complexity: simple rules for the known environment, dynamic or adaptable norms for the dynamic environment, systemic rules for the complicated environment for $\mathrm{CW}$ for the complex environment.

\section{Conclusion}

$\mathrm{CW}$ is the capacity for a group of individuals to envision a future and reach it in a complex context. By using the nervous system metaphor $\mathrm{CW}$ is the ability to identify patterns in the world, encode these patterns in some medium, and utilize this patterned medium to make useful, non-random decisions. $\mathrm{CW}$ is a form of choice architecture that could be installed into democratic general rulemaking (at least for more complex, dynamic problems). The emphasis is on the citizens' knowledge who, together with authorities' pattern policies. The more and more increasing complexity of regulation of society prevents the classical idea of society's management to be fully apprehended in legal norms. Since this is not possible, an increasing gap opens between the formal determination of rights and obligations and their actual implementation. The theory of complex systems could with an analysis of complexity that looks for patterns in a simple behaviour from a data set with the concept of emergence give a new perspective on a rule's understanding: an essential difference from the present understanding is not only that the collective as a whole represents more than just the sum of its parts. Only appropriately sized (numerically) dominated diversity

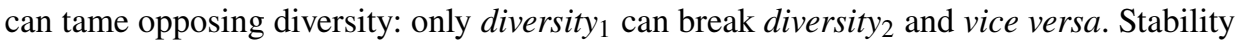
of a dynamical system is, therefore, the property of the system (and not of the people as individuals) as a whole; stability means the coordination of measures between the system's parts.

$\mathrm{CW}$ is about the inclusion of all diverse information, where the essential creator is the people, our evolutionary skills of selection that look for relevant information but grouped in a common pattern. This paper claims that events cannot be satisfactorily regulated if diversity is not similar on the side of regulator and the side of regulated; emergence is the cause that complex systems cannot be precisely predicted in advance; an awareness (of self and others) is the basis of every management; the implementation of awareness is possible through sensors that measure previously given criteria that allow the fact-finding and adapting to new circumstances. These inferences show that public systems and their decisions cannot be built solely based on the information we have, because it is the system of different sensors in different places with the detection of data (similar as the installation of 
sensors in the plane allows you to fly properly or promptly to respond to the surroundings) that enables deduction on appropriateness of some sort of regulation. It is not about to be able based on facts to make the best decisions and ex-post enforce also subjective responsibility for mistakes, but to have also the ex-ante system of facts perception that is designed to allow the detection of a wide range of data from which patterns can be seen. First, it is necessary to have relevant data (which we recognise/understand as such), and only then it can be analysed and placed in mutual relations. Mechanical - by the hand of one or some experts - rules can cope neither with dynamic nor with the complex environment. If this is common sense, it is not so common in the present parliamentarian and bureaucratic procedures. Decreased costs of IT should change the public decisionmaking processes, but further efforts are needed to undermine the Motorhead lyrics that 'everything changes, [but] all stays the same'. Let this paper be one small step towards CW.

\section{References}

Adolphs, R., Tranel, D. and Damasio, A. R. (1998). The human amygdala in social judgment. Nature, 393(6684), 470-474, https://doi.org/10.1038/30982.

Ariely, D. (2008). Predictably Irrational: The Hidden Forces That Shape Our Decisions. HarperCollins.

Aristotle. (1992). Eudemian Ethics Books I, II, and VIII (M. Woods, Trans.). Clarendon Press.

Aristotle. (1998). Politics (C. D. C. Reeve, Trans.). Hackett Publishing Company.

Aristotle. (2004). Nicomachean Ethics (R. Crisp, Ed.). Cambridge University Press.

Aristotle. (2012). Rhetoric. Indoeuropeanpublishing.com.

Ashby, W. R. (1957). An Introduction to Cybernetics. Chapman and Hall.

Ayres, I. (2007). Super Crunchers: Why Thinking-By-Numbers is the New Way to Be Smart. Bantam Books.

Baron, J. (1998). Judgment Misguided: Intuition and Error in Public Decision Making. Oxford University Press.

Bon, G. L. (2001). The Crowd: A Study of the Popular Mind. Batoche Books.

Brabham, D. C. (2013). Crowdsourcing. MIT Press.

Briskin, A., Erickson, S., Ott, J. and Callanan, T. (2009). The Power of Collective Wisdom and the Trap of Collective Folly. Berrett-Koehler Publishers.

Capra, F. (1997). The Web of Life: A New Scientific Understanding of Living Systems. Anchor Books.

Capra, F. and Luisi, P. L. (2014). The Systems View of Life: A Unifying Vision. Cambridge University Press.

Carnap, R. (1966). Philosophical Foundation of Physics: An Introduction to the Philosophy of Science (M. Gardner, Ed.). Basic Books.

Carrier, R. (2012). Proving History: Bayes's Theorem and the Quest for the Historical Jesus. Prometheus Books.

Christian, B. and Griffiths, T. (2016). Algorithms to Live By: The Computer Science of Human Decisions. Henry Holt and Co. 
Dawes, R. M. (1979). The robust beauty of improper linear models in decision making. American Psychologist, 571-582.

Dunning, D., Griffin, D. W., Milojkovic, J. D. and Ross, L. (1990). The overconfidence effect in social prediction. Journal of Personality and Social Psychology, 58(4), 568-581, https://doi.org/10.1037/0022-3514.58.4.568.

Dyer, D. (2020). The Return of Collective Intelligence: Ancient Wisdom for a World out of Balance. Simon and Schuster.

Edwards, W., Jr, R. F. M. and Winterfeldt, D. von. (2007). Advances in Decision Analysis: From Foundations to Applications. Cambridge University Press.

Engel, D., Woolley, A. W., Jing, L. X., Chabris, C. F. and Malone, T. W. (2014). Reading the Mind in the Eyes or Reading between the Lines? Theory of Mind Predicts Collective Intelligence Equally Well Online and Face-To-Face. PLOS ONE, 9(12), e115212, https://doi.org/10.1371/journal.pone.0115212.

Feynman, R. P., Leighton, R. B. and Sands, M. (1965). The Feynman Lectures on Physics, Vol. (Later Printing edition). Addison Wesley.

Galton, F. (1889). Natural inheritance. MacMillan and Co.

Galton, F. (1907). Vox Populi. Nature, 75, 450-451, https://doi.org/10.1038/075450a0.

Gamerman, D. (1997). Markov Chain Monte Carlo. Chapman and Hall/CRC.

Gerrits, L. and Marks, P. (2017). Understanding Collective Decision Making: A Fitness Landscape Model Approach. Edward Elgar Publishing.

Goleman, D. (2007). Social Intelligence: The New Science of Human Relationships. Bantam.

Grass, D., Caulkins, J. P., Feichtinger, G., Tragler, G. and Behrens, D. A. (2008). Optimal Control of Nonlinear Processes: With Applications in Drugs, Corruption, and Terror. Springer Science \& Business Media.

Grier, D. A. (2013). Crowdsourcing For Dummies. John Wiley \& Sons.

Grove, W. M. and Meehl, P. E. (1996). Comparative Efficiency of Informal (Subjective, Impressionistic) and Formal (Mechanical, Algorithmic) Prediction Procedures: The Clinical-Statistical Controversy, 2(2), 293-323.

Gulick, L. (2003). Notes On the Theory of Organisation. In K. Thompson (Ed.), The Early Sociology of Management and Organizations: Papers on the Science of Administration: Vol. IV (pp. 1-49). Routledge.

Haidt, J. (2012). The Righteous Mind: Why Good People are Divided by Politics and Religion. Pantheon Books.

Hammond, K. R. (1996). Human Judgment and Social Policy: Irreducible Uncertainty, Inevitable Error, Unavoidable Injustice. Oxford University Press, USA.

Hayek, F. A. (1998). Law, Legislation and Liberty: A New Statement of the Liberal Principles of Justice and Political Economy. Routledge.

Heisenberg, W. (1958). Physics and Philosophy: The Revolution in Modern Science. Harper \& Brothers Publishers.

Holland, J. H. (2006). Studying Complex Adaptive Systems. Journal of Systems Science and Complexity, 19(1), 1-8, https://doi.org/10.1007/s11424-006-0001-z.

Hume, D. (2009). A Treatise of Human Nature. The Floating Press. 
Janis, I. L. (1980). Groupthinking. In H. J. Leavitt, L. R. Pondy and D. M. Boje (Eds.), Readings in Managerial Psychology. University of Chicago Press.

Johnson, N. L. (2002). The Development of Collective Structure and Its Response to Environmental Change (SSRN Scholarly Paper ID 2232154). Social Science Research Network. https://papers.ssrn.com/abstract=2232154.

Kahneman, D. (2013). Thinking, Fast and Slow (Reprint edition). Farrar, Straus and Giroux. Kaplan, J. M. (2012). Rational Decision Making: Descriptive, Prescriptive, or Explanatory? In A. Nelson (Ed.), A Companion to Rationalism. John Wiley \& Sons.

Landemore, H. and Elster, J. (Eds.). (2012). Collective Wisdom: Principles and Mechanisms. Cambridge University Press.

Lanza, R. and Berman, B. (2013). Biocentrism: How Life and Consciousness are the Keys to Understanding the True Nature of the Universe. BenBella Books, Inc.

Lazarsfeld, P. F. (1949). The American Soldier-An Expository Review. The Public Opinion Quarterly, 13(3), 377-404. JSTOR.

Lee, K.-F. (2018). AI Superpowers: China, Silicon Valley, and the New World Order. Houghton Mifflin Harcourt.

Lorenz, J., Rauhut, H., Schweitzer, F. and Helbing, D. (2011). How social influence can undermine the wisdom of crowd effect. Proceedings of the National Academy of Sciences, 108(22), 9020-9025, https://doi.org/10.1073/pnas.1008636108.

Luhmann, N. (1990). Essays on Self-reference. Columbia University Press.

Luhmann, N. (2004). Law as a Social System (F. Kastner, R. Nobles, D. Schiff and R. Ziegert, Eds.; K. A. Ziegert, Trans.). Oxford University Press.

Malone, T. W. (2003). Is Empowerment Just a Fad? Control, Decision Making, and IT. In T. W. Malone, R. Laubacher and M. S. S. Morton (Eds.), Inventing the Organizations of the 21st Century. The MIT Press.

Malone, T. W. (2018). Superminds: How Hyperconnectivity is Changing the Way We Solve Problems. Oneworld Publications.

Marois, R. and Ivanoff, J. (2005). Capacity limits of information processing in the brain. Trends in Cognitive Sciences, 9(6), 296-305, https://doi.org/10.1016/j.tics.2005.04.010.

Maturana, H. R. and Varela, F. J. (2012). Autopoiesis and Cognition: The Realization of the Living. Springer Science \& Business Media.

Meadows, D. H. (2008). Thinking in Systems: A Primer. Chelsea Green Publishing.

Meehl, P. E. (2013). Clinical Versus Statistical Prediction: A Theoretical Analysis and a Review of the Evidence. Echo Point Books \& Media.

Milgram, S. (1967). The Small World Problem. Psychology Today, 2, 60-67.

Miorandi, D., Maltese, V., Rovatsos, M., Nijholt, A. and Stewart, J. (2014). Social Collective Intelligence: Combining the Powers of Humans and Machines to Build a Smarter Society. Springer.

Newton, I. (1675). Isaac Newton letter to Robert Hooke, 1675. Retrieved from https://discover.hsp.org/Record/dc-9792/.

Nielsen, T. D. and Jensen, F. (2007). Bayesian Networks and Decision Graphs (2nd edition). Springer. 
Oliveira, O. P. de. (2017). International Policy Diffusion and Participatory Budgeting: Ambassadors of Participation, International Institutions and Transnational Networks. Springer.

O'Reilly, T. (2010). Government as a Platform. In D. Lathrop and L. Ruma (Eds.), Open Government: Collaboration, Transparency, and Participation in Practice. O'Reilly Media, Inc.

Page, S. E. (2008). The Difference: How the Power of Diversity Creates Better Groups, Firms, Schools, and Societies. Princeton University Press.

Page, S. E. (2010). Diversity and Complexity. Princeton University Press.

Page, S. E. (2018). The Model Thinker: What You Need to Know to Make Data Work for You. Basic Books.

Parsons, T. (1985). Talcott Parsons on Institutions and Social Evolution: Selected Writings. University of Chicago Press.

Parsons, T. (1991). The Social System (New edition). Routledge.

Pielke Jr, R. A. (2007). The Honest Broker: Making Sense of Science in Policy and Politics. Cambridge University Press.

Premack, D. and Woodruff, G. (1978). Does the chimpanzee have a theory of mind? Behavioral and Brain Sciences, 1(4), 515-526, https://doi.org/10.1017/S0140525X00076512. Radin, D., Galdamez, K., Wendland, P., Rickenbach, R., Delorme, A. and Michel, L. (2012). Consciousness and the double-slit interference pattern: Six experiments. Physics Essays, 25(2), 157-171.

Ridley, M. (2017). What Charles Darwin owes Adam Smith. Retrieved from https://www. learnliberty.org/blog/what-charles-darwin-owes-adam-smith/.

Rosling, H., Rönnlund, A. R. and Rosling, O. (2018). Factfulness: Ten Reasons We're Wrong About the World - and Why Things Are Better Than You Think. Hodder \& Stoughton Ltd.

Rousseau, J.-J. (2002). The Social Contract and The First and Second Discourses (S. Dunn, Ed.). Yale University Press.

Russell, B. (2015). Why Men Fight: A Method of Abolishing the International Duel (Kindle Edition). Lulu Press, Inc.

Sarewitz, D. (2004). How science makes environmental controversies worse. Environmental Science \& Policy, 7(5), 385-403, https://doi.org/10.1016/j.envsci.2004.06.001.

Schwartz, B. and Sharpe, K. (2011). Practical Wisdom: The Right Way to Do the Right Thing. Riverhead Books.

Seligman, M. E. P., Railton, P., Baumeister, R. F. and Sripada, C. (2016). Homo Prospectus. Oxford University Press.

Shadbolt, N., O'Hara, K., Roure, D. D. and Hall, W. (2019). The Theory and Practice of Social Machines. Springer.

Shanteau, J. (1992). Competence in experts: The role of task characteristics. Organizational Behavior and Human Decision Processes, 53(2), 252-266, https://doi.org/10.1016/ 0749-5978(92)90064-E.

Silvertown, J. (2009). A new dawn for citizen science. Trends in Ecology \& Evolution, 24(9), 467-471, https://doi.org/10.1016/j.tree.2009.03.017. 
Simon, H. A. (1997). Administrative Behavior (4th Edition). Free Press.

Slovic, P. (1987). Perception of Risk. Science, 236(4799), 280-285.

Smart Society Project. (2017). Smart Society Project | 'Hybrid and Diversity-Aware Collective Adaptive Systems: When People Meet Machines to Build a Smarter Society'.

Stasser, G. and Titus, W. (1985). Pooling of unshared information in group decision making: Biased information sampling during discussion. Journal of Personality and Social Psychology, 48(6), 1476-1478.

Sunstein, C. R. (2006). Infotopia: How Many Minds Produce Knowledge. Oxford University Press.

Sunstein, C. R. (2009). Going to Extremes: How Like Minds Unite and Divide. Oxford University Press.

Sunstein, C. R. (2017). \#Republic: Divided Democracy in the Age of Social Media. Princeton University Press.

Surowiecki, J. (2005). The Wisdom of Crowds (Reprint edition). Anchor.

Taleb, N. N. (2010). The Black Swan: The Impact of the Highly Improbable Fragility (Kindle Edition). Random House Publishing Group.

Tetlock, P. and Gardner, D. (2015). Superforecasting: The Art and Science of Prediction (Kindle edition). Random House.

Tovey, M. (Ed.). (2008). Collective Intelligence: Creating a Prosperous World at Peace. Earth Intelligence Network.

Tversky, A. and Kahneman, D. (1974). Judgment under Uncertainty: Heuristics and Biases. Science, 185(4157), 1124-1131, https://doi.org/10.1126/science.185.4157.1124.

Varoufakis, Y. (2002). Foundations of Economics: A Beginner's Companion. Routledge.

Watts, D. J. (2011). Everything Is Obvious: *Once You Know the Answer. Crown Publishing Group.

Watts, D. J. (2018). Small Worlds: The Dynamics of Networks between Order and Randomness. Princeton University Press.

Wellman, W. A. (1947, October 7). Magic Town [Comedy, Romance]. Robert Riskin Productions.

Willy, C., Neugebauer, E. A. M. and Gerngroß, H. (2003). The Concept of Nonlinearity in Complex Systems. European Journal of Trauma, 29(1), 11-22, https://doi.org/10.1007/ s00068-003-1248-X.

Woods, M. and Aristotle. (1992). Commentary. In M. Woods (Trans.), Eudemian Ethics Books I, II, and VIII. Clarendon Press.

Woolley, A. W., Chabris, C. F., Pentland, A., Hashmi, N. and Malone, T. W. (2010). Evidence for a Collective Intelligence Factor in the Performance of Human Groups. Science, 330(6004), 686-688, https://doi.org/10.1126/science.1193147

Worthington, J. P., Silvertown, J., Cook, L., Cameron, R., Dodd, M., Greenwood, R. M., McConway, K. and Skelton, P. (2012). Evolution MegaLab: A case study in citizen science methods. Methods in Ecology and Evolution, 3(2), 303-309, https://doi.org/10.1111/j.2041-210X.2011.00164.x

Yoshida, Z. (2010). Nonlinear Science: The Challenge of Complex Systems (Heidelberg). Springer. 